\title{
ANÁLISIS DE CONVERSACIONES EN TRES DRAMATIZACIONES INFANTILES: CARACTERÍSTICAS DEL DISCURSO
}

\author{
Laura Ramírez Saborio*
}

\begin{abstract}
RESUMEN
En esta investigación se analizan tres conversaciones de dramatizaciones infantiles en dos períodos de juego en el kínder (casita y pulpería), con el objetivo de analizar el discurso infantil, visto como proceso.
\end{abstract}

\begin{abstract}
In this research, we analyze three conversations from children dramatizations in the kindergarden in two sessions of play (casita and pulpería), in order to analize child discourse as a process.
\end{abstract}

\section{Introducción}

Para el analista del discurso, es interesante estudiar las regularidades de las conversaciones infantiles por varias razones:

1. El lingüista está encargado de conocer y explorar cuáles son las características del lenguaje infantil.

2. Este estudio tiene más sentido cuando se pone a disposición de profesionales que las necesitan: por ejemplo los maestros, los antropólogos y los estudiosos de la socio y la psicolingüística.

3. El análisis del discurso retoma un aspecto fundamental del desarrollo y la adquisición del lenguaje: el contexto.

Por otro lado, debe considerarse el discurso como un proceso y no como un producto - como lo señalan Brown y Yule 1993 - en el que se dan una serie de presuposiciones, inferencias e implicaturas. En ese sentido, es necesario contextualizar el tiempo, el espacio, los hablantes y los oyentes - participantes en general-, el co-texto, montaje, etc, que intervienen en el desarrollo el discurso.

Estos elementos son fundamentales para hacer un análisis válido que permita al analista adoptar una visión más pragmática al estudiar el lenguaje en uso. 
En esta investigación se intenta retomar estas ideas, al analizar tres conversaciones de dramatizaciones infantiles. Con el objetivo de analizar el discurso infantil en tres períodos de juego en el kínder (casita y pulpería), se exponen algunos planteamientos teóricos sobre el análisis del discurso infantil así como la forma en que se obtuvo el corpus. Por otro lado, se describen las características del discurso infantil —como proceso- que intervienen en las dramatizaciones infantiles.

Finalmente se señala, de acuerdo con el análisis de la conversación, las regularidades que se presentan en el discurso del juego dramático de los niños preescolares.

\section{Aspectos teóricos}

\subsection{Discurso infantil: interpretación y conocimiento de la conversación}

En el artículo escrito por Sacks (1986), se realiza un análisis en relación con cuentos contados por infantes. Sacks trabaja con conversaciones naturales, auténticas, y busca descubrir cómo su estructura y sus recursos reflejan el conocimiento social de los hablantes. Plantea un aparato conceptual para el estudio empírico de las maneras en que el razonamiento práctico se usa en el discurso cotidiano.

Además, se centra especialmente en los intercambios verbales entre los hablantes y estudia las estrategias semánticas y teóricas por las cuales los hablantes se identifican o reaccionan con otros.

Sacks analiza el uso de los sustantivos y verbos particulares como 'madre', 'bebé' o actividades como 'hacer moda' o 'tener problemas sexuales', que sirven como marcadores de relaciones sociales. Su objetivo es demostrar cómo los oyentes deben utilizar su propio conocimiento del sistema social para interpretar la yuxtaposición de estos términos en la conversación. Trata de demostrar la necesidad del oyente de utilizar su conocimiento social en tres formas:

1. Para reconocer grupos particulares de oraciones como instancias posibles de descripciones, cuentos, conversaciones, etc.

2. Para lograr ciertos efectos sociales: responder, hacer un favor, etc.

3. Para comunicar el afecto: crítica o humor.

Sacks no investiga el 'porqué' de la acción en cuestión, sino que se preocupa por cómo la acción en cuestión se hace inteligible e interpretable.

Para este lingüista, las normas sociales son una parte del código comunicativo que gobierna nuestra percepción de los hechos, así como la gramática gobierna nuestra percepción del habla. (Sacks 1986: 327). Si se quiere entender qué es lo que un hablante — señala Sacksquiere lograr con lo que dice, tenemos que estar familiarizados con las categorías sociales que utiliza y las asociaciones culturales que estas llevan. 
En relación con los 'Problemas con el reconocimiento de descripciones posibles', Sacks (1986: 329) comienza con las primeras dos oraciones de un cuento hecho por una niña de dos años y nueve meses que ofrece al autor del libro Children Tell Stories:

\section{"The baby cried. The mommy picked it up".}

De acuerdo con estas oraciones, Sacks hace unas observaciones de las posibles formas de interpretar:

1. Él entiende que la mamá que alza el bebé es la mamá del bebé.

2. Muchos hablantes del inglés entenderían lo mismo.

3. La segunda oración sigue a la primera.

Una de las tareas de Sacks es construir un aparato que muestre, por ejemplo, cómo es que llegamos a oir un fragmento en la forma en que lo hacemos; es decir cómo hay una serie de reglas socialmente determinadas que nos inducen a interpretar las cosas de cierta manera.

Con respecto a las dos frases explica cómo para un hablante puede tener algunas implicaturas y para otros, otras. Así es como quiere demostrar el poder de una cultura a la hora de hacer posibles descripciones.

Por lo anterior, se deduce que la cultura tiene poder en el reconocimiento de las descripciones.

El segundo punto tratado por Sacks (1986: 333) es la categorización de miembros de los colecciones de categorías que se pueden unir. El autor da el ejemplo de "bebé" y "mamá", qe caben juntos en la categoría de la familia. En casos de ambigüedad de la categoría de un miembro, se aplica la regla de consistencia que dice que si una población de personas está siendo categorizada, esta categoría puede servir a los demás miembros de la población, y la regla de economía que señala que una sola categoría puede ser referencialmente adecuada.

Otro punto es el de límite de categoría de actividades (category-bound activities) (1986: 335) donde Sacks apunta que muchas actividades son tomadas por los miembros donde las categorías son categorías de miembros de colecciones o dispositivos. Ejemplo: 'llorar' es un límite para el bebé. La categoría 'bebé' es un miembro de la colección del 'dispositivo', 'escenario de vida'.

El cuarto punto es la identificación de posibles descripciones (1986: 338) y señala que una actividad puede ser considerada con respecto a lo 'correcto' para los miembros de 'una posible descripción'. Lo de correcto es reconocible y hay dos posibles lazos entre una descripción reconocible correctamente y el reconocimiento de observaciones correctas. En el análisis utiliza dos máximas: la del observador y la del oyente.

\subsection{Elementos por considerar en análisis del discurso}

Brown y Yule (1993) señalan que el analista del discurso debe adoptar un enfoque pragmático al estudiar el lenguaje en uso. El acercamiento del analista a los datos lingüísticos difiere del lingüista formal en otros aspectos y conduce al uso especializado de términos, ya que describe lo que hacen hablante y oyentes. 
Algunos elementos que intervienen en el contexto de la interpretación son:

1. La referencia: "referir no es algo que haga una expresión; es algo para cuya realización puede alguien emplear una expresión". Se considera la referencia como una acción del hablante/escritor.

2. La presuposición: la que se define en términos de los supuestos que el hablante hace sobre lo que probablemente aceptará el oyente sin dudarlo.

3. Las implicaturas: Grice utiliza este término para dar cuenta de lo que un hablante puede implicar, sugerir o querer decir cuando esto es distinto de lo que dice literalmente. Hay implicaturas convencionales que están determinadas por el significado convencional de las palabras empleadas. Las convenciones conversacionales o máximas que se desarrollan del Principio de Cooperación son: cantidad, cualidad, relación y manera. Las implicaturas son aspectos pragmáticos del significado.

4. La inferencia: el analista tiene que apoyarse en un proceso de inferencia para llegar a una interpretación de los enunciados y de las relaciones entre ellos. Los términos referencia, presuposición, implicatura e inferencia deben ser considerados conceptos pragmáticos (1993: 49-56).

Asimismo el contexto de situación es fundamental para entender los enunciados e interpretarlos; entre ellos están:

Rasgos del contexto: papeles del emisor, el destinatario, audiencia, tema, marco, canal, código, forma del mensaje, acto, clave y propósito (rasgos etnográficos propuestos por Hymes). Lewis propone coordenadas que son un conjunto de factores relevantes, un índice y que caracterizan el contexto: mundo posible, tiempo, espacio, hablante, audiencia, objeto indicado, discurso previo y asignación. Estos rasgos permiten una explicación del término contexto. Si se alteran las condiciones especificadas por cualquiera de las coordenadas, se altera el contexto. Las distintas inferencias surgen a partir de la alteración del contexto, por la sencilla manipulación de la edad y el sexo del emisor.

El co-texto: dentro del co-texto, puede construirse otro contexto más con su propio índice de coordenadas y en ese contexto construido pueden encajarse otros contextos. El texto crea su propio contexto (1993: 59-70).

$\mathrm{El}$ analista debe extraer aquellas propiedades de los rasgos del contexto que sean pertinentes en cada acto particular y que contribuyan a la interpretación.

\subsection{Ubicación de la etapa de desarrollo humano de los preescolares: de 5 a 6 años}

La llamada primera infancia se ubica de antes del nacimiento hasta los seis años y es fundamental porque en ella se crean las bases del desarrollo del individuo (Hurlock citado en el MEP. 1996: 3). 
En este estudio sobre el discurso de niños preescolares, se describe en forma general el período de desarrollo de 5 a 6 años, ya que el corpus que se analiza corresponde a niños de esta edad. Se analizan actividades de juego espontáneas en un centro infantil. La ubicación que se realiza se hace con base en el programa de estudios del MEP, 1996.

La edad preescolar se ubica en el período llamado preoperacional (2-6 años) donde el niño comienza a interiorizar sus acciones y a emplear en forma creciente el juego simbólico y de lenguaje (Terminología empleada por Piaget).

El MEP posee una fundamentación teórica para el área cognoscitiva-lingüística y señala que el pensamiento preoperatorio de los niños se caracteriza por:

egocentrismo: el niño es incapaz de distinguir el punto de vista de los demás centración: en rasgos superficiales del objeto irreversibilidad: es incapaz de efectuar un razonamiento y luego el camino inverso. animismo: cree que las cosas están vivas artificialismo: según el niño, que las cosas proceden de las acciones de un agente exterior y no obedecen a procesos naturales.

Con respecto del lenguaje, señalan un objetivo del programa que es el siguiente:

\begin{abstract}
...favorecer la capacidad comunicativa debe ser la acción PERMANENTE del proceso educativo, porque por medio del lenguaje los niños estructuran el conocimiento del mundo, amplían su capacidad de actuar sobre las cosas, les permite integrarse como personas a su cultura, las conduce a la socialización de sus actos, de manera tal que su pensamiento individual se refuerza ampliamente a través de la trasmisión social y constituye la forma más usual, eficaz y directa que posee el ser humano (1996: 6).
\end{abstract}

\title{
3. Procedimiento metodológico: recolección y obtención de datos
}

\subsection{Corpus: descripción y general obtención}

El corpus que se utilizará en este trabajo fue el utilizado y recolectado por Ramírez (1996), basado en juegos realizados por niños preescolares en un centro infantil privado. Los juegos son de tipo pretendidos, en los que los niños imitan ciertos papeles no solo en el nivel de actuación sino también en el nivel lingüístico, es decir, en su discurso.

\subsubsection{Datos generales}

Lugar específico: centro infantil privado.

Nivel: preparatoria

Docente: tiene el grado profesional de bachillerato en educación preescolar y estudiante de licenciatura en psicopedagogía. El criterio de elección de esta docente se realizó con base en su disposición para realizar las grabaciones e interés en el tema.

Períodos grabados (corpus): Un total de 3 grabaciones magnetofónicas. Período: juego-trabajo. Áreas de casita y pulpería (dramatización de papeles). Solamente se cuenta con las 
conversaciones. No hay ningún tipo de observación participante por parte de la investigadora. Las únicas observaciones que se consideran son las realizadas por la docente.

Tiempo aproximado de cada grabación: 30 minutos

\subsubsection{Obtención del corpus}

El corpus obtenido para este estudio fue recolectado en un centro infantil privado, en el nivel de preparatoria con niños de 5 a 6 años (4 niñas y 2 niños). Las grabaciones se realizaron en un grupo de preparatoria y se utilizaron tres períodos de trabajo. La elección del centro infantil y del grupo en cuestión se realizó con criterios basados en la disposición e interés por parte de la maestra, así como la anuencia de los niños a ser grabados.

El juego se organiza por áreas, no es dirigido. Es decir, los niños de forma espontánea y con los materiales que tienen, crean una situación, que puede ser real o inventada - como la dramatización de papeles-. La única intervención de la maestra es para observar y analizar los acciones, de forma que ella rota por las diferentes situaciones de trabajo y juego que se desarrollan en el aula.

Los niños utilizan y recogen los materiales que necesitan. Estas áreas de trabajo pueden desarrollarse dentro o fuera del aula, con un espacio definido o creado. En este caso se hace fuera del aula.

\subsubsection{Observaciones realizadas por la docente a cargo del grupo}

1. Por lo general juegan en estas áreas más niñas que niños. La población femenina casi dobla a la masculina en este salón de clase. 12 niñas, 7 niños.

2. Usualmente van dos niños. A uno le interesa porque hay pinturas y el otro juega el papel de "papá".

3. No suele dar el área de casita por el trabajo y tiempo de exploración que requiere por parte de los niños (vestirse, repartir papeles, etc).

4. Los niños juegan al aire libre.

5. El uso del teléfono se da por parte de las niñas y frases como: Chao, mirá, te tengo que contar. Regañan, dan quejas al esposo.

6. Los gestos que utilizan: imitaciones de las mamás.

7. El niño-papá se viste y se va para el trabajo.

8. En las familias del grupo hay por lo menos un profesional que trabaja.

9. Las dos niñas y las figuras femeninas en su casa: una no trabaja y la otra lo hace medio tiempo. 


\section{Análisis del corpus}

Para el análisis del corpus, se utilizó una muestra de análisis de la conversación realizada por Schiffrin (1994).

Señala el siguiente ejemplo:

"there + BE+ ITEM"

Fórmulas como esta le permitían descubrir a Schiffrin las regularidades que había en ciertas conversaciones.

En el siguiente ejemplo hay una construcción there utilizada por el dueño de la biblioteca, que es (P) en una entrevista con el bibliotecario (L). La construcción there se centra en el ítem para el cual $\mathrm{P}$ está investigando:

$\longrightarrow$ P: $\quad$ (j) There used to be a monthly report that comes from S- Securities Exchange Commission...on insider's transactions $=$

L: $\quad$ (k) Uh huh

P: $\quad(1)=$ and many years ago you used to carry it

(m) and I haven't seen it in a long time (Schiffrin 1994: 240)

Además, Schiffrin expone unas fórmulas más específicas que le conducían a realizar un análisis más amplio y establecer otros patrones en el proceso discursivo, siempre con la forma base There + BE+ ITEM. Algunos ejemplos son:

1. "Menciones", "There + BE+ ITEM" y pares adyacentes

2. "There + BE+ ITEM" en pares independientes de pregunta/respuesta

3. "There + BE+ ITEM" y la organización de turno a la hora de hablar

4. "There + BE+ ITEM" y la organización de tópico

5. "There + BE+ ITEM" y la organización de menciones (Schiffrin: 239-65).

Es decir, que cada vez que aparecía en la conversación una forma como la 2, la señalaba con una flecha y hacía una comparación y una relación con formas similares como en este ejemplo:

Iver: (a) Were there any social functions that the church had that you kids went to?

Ivee: (b) Not me, no. (Schiffrin, 1994: 243).

De acuerdo con la exposición anterior se propusieron las siguientes categorías para analizar el discurso infantil. Algunas de las definiciones están basadas en la taxonomía de Murillo y Chacón (1995: 145-152):

\section{Pregunta / respuesta :}

En esta categoría pueden encontrarse pares adyacentes en el discurso. Asimismo, se incluye en esta categoría solo la pregunta o solo la respuesta. Expone en forma de interrogación un asunto, bien para indicar duda o vigorizar la expresión. (DRAE 1992: 1656). Ej: ¿De quién es esto? 


\section{Fomas imperativas-orden:}

Acto de habla directivo para que el oyente actúe de una forma determinada. Esta es una forma de definir las formas de imposición que se desarrollan en el corpus. Están ejemplificadas por formas como: "Tiene que", "Haga", "Usted se pone eso".

\section{Afirmación /Negación:}

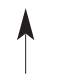

La declaración o negación de un hecho dentro del contexto lingüístico.

4. Petición:

$\downarrow$

Proponer a alguien algo que convenga a la persona que lo sugiere de forma amable o persuasiva. En esto difiere de la categoría 2. En algunas ocasiones es una pretensión. Ej: "Ay, digamos que nosotros no tenemos papás". "Por favor..."

\section{Amenaza:}

Intervención que anticipa una consecuencia para el oyente si no actúa de una forma determinada. Ej: "si disparas yo te mato a ti". "Y te pinto las uñas".

\section{Información}

Hace del conocimiento de los demás algo.

Donde aparezcan estas regularidades en el discurso de cualquiera de los tres actos, se señala con una flecha y el color la categoría presente según lo indicado arriba. Cada línea tendrá su número para mejor ubicación. Se hace un comentario después de cada regularidad descubierta en los tres actos verbales.

El siguiente es el orden del análisis:

1. Fórmulas regulares encontradas en cada acto.

2. Se señalan con una flecha las categorías - fórmulas planteadas, con el número de línea y acto correspondiente.

3. Comentarios por cada categoría, relacionando los tres actos.

4. El corpus total puede verse en los anexos.

\subsection{Preguntas/Respuestas}

En general parece que las preguntas hechas por los niños tiene un carácter más mitigado que el de las niñas. Las preguntas de ellas son más desafiantes y de imposición de liderazgo que las de los niños. En los tres actos, se encuentran estas formas. Algunas preguntas no tienen respuestas, pero esta fórmula es constante en el discurso.

\section{I acto: casita}

1. Niño: ¿Qué es eso ? 
3. Niños: ¿Para qué ocupamos esto?

4. Niña: ¿Dónde está el de los labios?

6. Parte A: ¿Qué nos ponemos ?

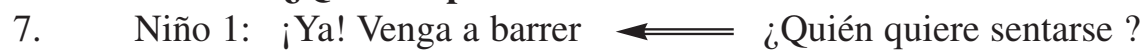

8. Niña: ¿Dónde está el bolso?

12. Niño 2: Ja, ja, ja ¿Verdad que los señores de la pulpería se visten ?

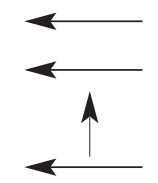

En este caso las preguntas no tienen respuestas, son un tipo de monológo colectivo, donde cada cual se expresa pero el interlocutor está ausente aunque sea oyente.

En la línea 7, por ejemplo, además hay una orden intercalada entre las preguntas. Pero hay otro tipo de caso como el siguiente:

\section{II acto: pulpería}

10. Niño 2: Es mejor comprar.

13. Niña: ¿Entonces por qué me están molestando a mí?

14. Niño 2: María es mejor comprar que vender.

Porque vender es muy feo.

15. Niña 1: Oiga: ¿por qué mejor no se calla?

17. Niña 1: Traigan los chiquitos que quieren comprar y la plata.

18. Niño 1: ¿Por qué ?

19. Niña 1: Porque sí. (Ella dice qué es lo que se vende).

24. Niño 1: ¿Usted va a vender?

25. Niña 1: Sí, yo voy a vender.

Usted va a comprar, usted va a comprar.

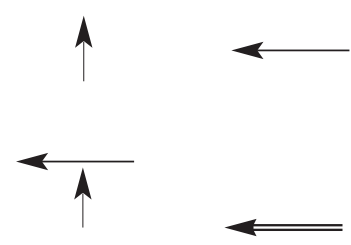

De nuevo una forma de preguntar y responder con una forma imperativa. En la línea 25 , hay tres categorías presentes.

29. Niña: ¿A usted qué se le ofrece ?

30. Niño: ¿Cuánto cuesta?

31. Niña: Dos billetes.

32. Niña: Señora ¿qué se le ofrece?

(el niño vendedor trata de intervenir)

33. Niña: Yo la atiendo a ella.

36. Niño: ¿Qué quiere?

37. Niña: Yo ya lo atendí.

Las formas de cortesía son inexistentes, pero hay más habilidad para la interacción lingüística.

44. Niño: ¿Tiene curitas? 
45. Niña: Y las curas. Además hay bolsas de basura, salsa lizano, gelatina,numar, jugo de naranja, chile, tomate.

47. Niño: Señor, ¿qué quiere?

48. Niña: ¿Qué desea?

49. Niño: ¿Cuánto cuesta?

50. Niña: Me tienen que preguntar.

\section{III acto: casita}

18. Niño $1:$ ¿Y por qué?

19. Niña1: Para jugar burrirrto

27. Niña 2: ¿Yo?

28. Niño 1: No gracias, porque le voy a ir a comprar unos confititos. ¿Usted qué? ¿Ella quién es?

35. Niña 2: Llena. ¿Bolsa de qué?

36. Niño 1: De confites.

37. Niña 2: ¡Ay gracias!

38. Niño 1: Bueno, van a cocinar la comida, ¿o qué?

39. Niña 1: Me voy a pintar las uñas.

48. Niña 1: A escobazos te saco a vos. ¿Podría ser?

49. Niña 2: Podría ser.

68. Niña 1: (A otro niño) ¿Se van a ir de aquí o qué?

69. Niño: No nos da la gana. Usted no nos manda.

70. Niño: Cuidado: nos están grabando.

71. Niño: ¿Y qué? A mí no me importa que me estén grabando.

86. Niño 1: ¿Qué quieres?

87. Niña 1: Hermano... Ya estás muy grande como para jugar caballito.

88. Niña 1: Ay sí, pero a mí me encanta jugar caballito.

96. Niño 1: Yo le enseño a disparar.

97. Niña 2: ¿De verdad?

98. Niño 1: Sí.

107. Niña 1: Ja, ja, ¿Antonio se pintó? Mejor un tiro.

108. Niña 2: Sí.

121. Niña 2. ¿Por qué?

122. Niño 1: Porque no quiere hacer caso, así que vete a tu cuarto. 
138. Niña 1. Papá: ¿puedo saltar suiza con tu corbata?

139. Niño 1: Sí.

141. Niño 1: ¿Quién se portó mal?

142. Niña 2: Este que no se quiere poner la inyección.

158. Niño 1: ¿La comida?

159. Niña 2: La comida está lista mamá, pero yo tengo mucho sueño. Yo me voy a dormir, aunque ya no tenga sueño.

En los tres actos las preguntas cumplen un papel fundamental: permiten que los niños sean parte del juego. No necesariamente existe una interacción permanente, pero queda claro que todos son participantes y que cada uno tiene una función particular. Las preguntas y las respuestas generan una conversación que pertenece a la idea del modelo de interacción familiar o comercial, que se presenta como el contexto lingüístico preferido para recordar cuál es el papel que cada cual debe cumplir. Ahora bien, como se observó, muchas de las preguntas no tienen una respuesta directa, pues hay cambios de tópico. Esto puede significar dos cosas:

1. Se generan monólogos colectivos, donde los hablantes hablan sin un interés particular de que sea escuchado lo que dice, es decir, habla por su simple deseo - egocéntrico- de hablar: característico de la edad preescolar.

2. Es una forma de obviar la pregunta o respuesta del hablante para no permitirle un espacio lingüístico y lúdico en la actividad.

Además, en el discurso no solo está la categoría de pregunta/respuesta sino que intervienen otras categorías como la información y la negación para dar coherencia al discurso.

\subsection{Imperativas-Orden}

\section{I acto: casita}

16. Niñas: Usted se pone eso.

17. Niña 1: Vístase.

19. Niña 1: Se lo tiene que poner. Usted se pone esto, usted se pone esto. La niña dijo que tenía que vestirse de papá.

20. Niña 2: Vístase .

21. Niño 1: Ustedes también tienen que vestirse (a las niñas).

22. Niñas: (A Niño 2) Tiene que ponerse eso.

\section{II acto: pulpería}

1. Niña 1: Yo soy la que vendo .

7. Niña 1: Usted sale, usted sale y usted sale.

8. Niña: Ellas dos compran . 
9. Niña 1: Bueno, María compra.

10. Niño 2: Es mejor comprar.

22. Niño 1: ¡Ya! Empecemos a jugar.

25. Niña 1: Sí, yo voy a vender. $\longrightarrow$ Usted va a comprar, usted va a comprar.

39. Niña (la vendedora): Usted tiene que preguntarme a mí.

42. Niña: Déme un billete (pelean por el vuelto).

46. Niña: Tiene que poner estos aquí.

50. Niña: Me tienen que preguntar.

\section{III acto: casita}

4. Niña 1: Ay ya, cállate por favor, ya me tienen loca.

6. Niña 2: Ya hermano, ya hermano, quítate ese sombrero.

9. Niño 1: No griten. (Niña 1 interrumpe)

10. Niña 2: Quítese hermano idiota (...)

17. Niña 1: En primero papá, te vas a quedar aquí.

22. Niña 1: Camine burrito.

23. Niña 1: Hija, papá camina bien rápido. Que no. Estás loco.

56. Niño 1: Urra, urr....un incendio. Todo mundo afuera de la casa.

62. Niño 1: Quítense que vengo a llevarme el extinguidor.

Pisssssh. (Niña sigue llorando.)

100. Niño 1: Dispárale.

120. Niño 1: Entonces, entonces estás castigada.

En los tres actos, el ítem de la imposición u orden es permanente. La persuasión para solicitar algo es casi nula excepto, como se verá, en la sexta categoría, donde hay algunas formas de cortesía. Las características de este discurso definen estos actos como un tipo discursivo agresivo. Claro está que se refieren al discurso, no al comportamiento. Las niñas muestran más formas imperativas, que en algunas ocasiones son respuestas a las actuaciones de los otros jugadores: es decir, se manifiesta la lucha por un espacio o una condición menos perjudicial. 


\subsection{Afirmación/Negación:}

\section{I acto: casita}

13. Niño 1: Ellos no tienen ropa de papás.

14. Niño 2: Ellos sí tienen ropa, veá. Mire, mire.

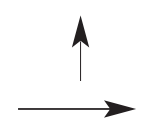

18. Niño 1: Eso no me lo pongo porque parezco una muchacha (una faja).

23. Niña 1: Hija, papá caminá bien rápido. Que no. Estás loco.

24. Niño 1: ¿Oyó? Ya no quiero jugar, chiquito.

\section{II acto: pulpería}

2. Niño 1: ¡Ah no! Yo también vendo.

11. Niña: No.

12. Niño: Sí.

19. Niña 1: Porque sí (ella dice qué es lo que se vende).

\section{III acto: casita}

55. Niña 1: A mí no me gustan los confites.

74. Niño 1: Aquí, todos tenemos que vivir en esta casa.

75. Niña 1: Yo no.

83. Niña 1: A jugar caballito.

84. Niño 1: No gracias.

85. Niña 1: ¡Ah sí!

93. Niña 1: Ay no. Hace de policía. (¡Qué aburrido!)

A jugar de policías con mujeres.

94. Niña 1: No.

113. Niño: $\mathrm{Y}$ ahora me voy a graduar

114. Niña 1: Actos de teatro. Gradúate si quieres ser actor de teatro.

115. (...)

116. Niño 1: No, gracias

117. Niña 2: Entonces yo no quiero karate.

Me voy a quedar aquí en la casa metida todo el día.

118. Niño: Bueno, si tú lo dices. Pero vieras que en la pulpería están vendiendo popis de los Power Rangers. Y de Troopers y de los Caballeros de la mesa redonda.

119. Niña 2: ¡Ah! Yo no los quiero. Son puras cosas feas.

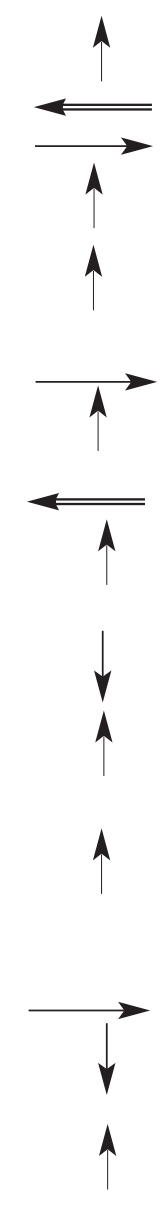


122. Niño 1: Porque no quiere hacer caso, así que vete a tu cuarto.

123. Niña 2: No me da la gana

124. Niño 1: Entonces pau, pau, pau.

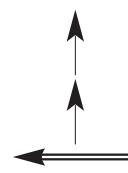

En general son más las negaciones que las afirmaciones. Asimismo estas negaciones son respuestas a imposiciones o preguntas que realiza el interlocutor. Muchas de las respuestas en forma de negación son realizadas por los niños como contraparte al discurso construido. Esta clase de contexto lingüístico permite observar la capacidad de habilidad e interacción lingüística entre los participantes en estos actos de habla. Esta interacción lingüística, como se observa en el análisis, está realizada con la mayoría de las categorías que se plantearon: preguntas/respuestas, peticiones, órdenes, etc.

\subsection{Petición}

\section{I acto: casita}

9. Niño 1: Sentados los chicos y chiquitas.

\section{II acto: pulpería}

3. Coro: Yo también quiero vender.

4. Niña: Alguien que compre.

5. (Hay una discusión acerca de quien compra y quien vende).

6. Niño 2. Yo quiero comprar.

41. Niña: Digamos que Maicol era el esposo.

53. Niño: María Angélica y yo vivíamos juntos

(el vendedor y la vendedora).

\section{III acto: casita}

1. Niño 1:Hijo, por favor ve a la pulpería y me traes (la niña dice:

Diego barría, sigue barriendo por todos lados) 15 paquetes de tortillas. Aquí tienes el sombrero.

8. Niña 2: Pero aquí todos están locos.

Cálmense.

15. Niño 1: Auxilio

26. Niña1: Ponte este sombrero para dormir.

91. Niña1: Ay sí....juguemos policías.

144. Niña 1: ¡Ay se murió el papá! 
145. Niño 1: Ay, digamos que nosotros no tenemos papás.

Que se murieron por un tiempillo.

146. Niño 2: Hay que hacerle un entierro al papá.

147. Todos: Vamos al entierro del papá.

148. Niña 1: Como ya tuvieron un hijo nuevo, vamos al entierro de papi.

149. Niño 1: Digamos que yo tenía dos años. Yo le hago caso a mi mamita.

La petición que es una categoría más bien mitigada que está presente en los tres actos, equilibrando las imperativas y los monológos. En esta intervenciones hay más acuerdo para llegar a una solución.

Ante el estilo discursivo caracterizado por las órdenes, aparecen las formas de pedir algo con un carácter más persuasivo. Estas peticiones por lo general son realizadas por parte de los niños a quienes se les impone actuar de determinada forma. En este sentido el resto de los niños -ante una niña líder- se solidarizan en el juego para generar su espacio y reinterpretar el juego a su modo.

Además, en las últimas líneas donde se plantea la muerte de los padres, se ve una estrategia del resto de los niños — que actuaron como hijos o hijas — para olvidar la imposición de los padres y los problemas, e iniciar otro tipo de juego. Casualmente es aquí donde inicia el final del juego. Se establece la necesidad de que alguien dirija el juego.

\subsection{Amenaza}

La amenaza no se presenta en el discurso del primer acto y tampoco en el segundo. Probablemente tenga relación directa con la situación propia de la actividad que no planteaba para los hablantes emitir una amenaza porque lo resolvieron con formas imperativas o persuasivas. No hizo falta -en estos actos- que se condicionara la posición de alguien porque el oyente o interlocutor o acató o hizo caso omiso de las órdenes. Sin embargo en el tercer acto de casita, la situación cambia. Hay que tomar en cuenta que la situación que reflejan es la de una familia con problemas: en algunos casos la agresión verbal se agudiza y se hace necesario plantear en el nivel oral respuestas a las agresiones planteadas. Lo que sucede es que igualmente responden con amenazas cuando sienten que se les está perjudicando de algún modo.

\section{III acto: casita}

11. Niño: No griten porque te voy a llevar al, porque sino te contigo $\mathrm{y}$ te tienes que encerrar en tu cuarto.

16. Niño 1: Cuidado con lo que hace, chiquita

47. Niño 1: Creo que algunos de los nos vamos a tener que sacar de la casa: Creo que algunos de los os vamos a tener que sacar de la casa. Creo que ya que quién es...Tú.

49. Niña 2: Podría ser. 
49. Niña 2: Ven conmigo (Niña1 llora)

103. Niño 1: ¡Conqué sí! Te voy a pintar con pintura de labios.

104. Niño: Y le digo a la niña.

105. Niña 2: Eh, como Antonio, ja, ja.

106. Niño 1: Nombré.

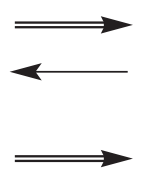

101. Niña 1: Si disparas yo te mato a ti. Y te pinto las uñas.

163. Niño 1: Le voy a dar un zapatazo. (...) Un vaso lleno de sangre y una inyección en el culo.

Estas amenazas finales afectan directamente y de forma muy negativa, estimulando miedos y prejuicios. La línea 101 que se refiere a pintarle las uñas a un niño y la 163, referida a una inyección, apunta a que a estas edades está definido por normas sociales, que las uñas sólo se las pintan las niñas y que la inyección se pone cuando un niño no tiene un buen comportamiento (y no porque haya un problema de salud). Con esto se confirman la creación de temores por parte de los adultos, los papeles que dramatizan estos niños.

\subsection{Información}

\section{I acto: casita}

10. Niña: Esta es la bolsa de pulpería.

11. Niño1: Yo no ocupo eso (a niña).

23. Niño 1: Yo tengo que ponerme un pantalón.

24. Niño 2: No tengo qué ponerme, no hay otro pantalón (insiste en que no hay pantalones para él).

25. Niña 2: No importa.

26. Niño 2: No hay más pantalón para mí.

27. Niña 2: Me voy a pintar.

\section{I acto: pulpería}

20. Niño 1: Ana Lucía compra.

23. Niña 1: Aquí vendemos aceite.

33. Niña: Yo la atiendo a ella .

34. Niño: Yo atiendo.

43. Niño: Señora, le vendo leche, jugo... (se escucha al fondo pero la atención esta concentrada en la vendedora). 
45. Niña: Y las curas. Además hay bolsas de basura, salsa lizano, gelatina, numar, jugo de naranja, chile, tomate.

51. Niño: A mí no me dio el vuelto.

\section{III acto: casita}

2. Niña 2: Pero yo no sé qué me pasa.

3. Niño 1: Mamá, mandé al hijo a traer 15 paquetes de tortillas porque $(. ..) \longrightarrow$

51. Niño 1: Me compré una bolsa llena de confititos.

55. Niña 1: A mí no me gustan los confites.

59. Niña 2: Hay un incendio.

63. Niña 2: (Grita). El incendio viene para acá. Auxilio.

64. Niño: No se preocupen. Ya lo apagué.

76. Niña. Y ya viene un juego partido.

77. Niña 2: Mejor me voy a una playa. Prefiero...

78. Niño 1: No se preocupen porque esos, es nada más para mortifiqueros.

79. Niña 2: Me voy para Playa Tambor.

80. Niño: Y yo también. Adiós.

117. Niña 2: Entonces yo no quiero karate. Me voy a quedar aquí en la casa metida todo el día .

118. Niño: Bueno, si tú lo dices. Pero vieras que en la pulpería están vendiendo popis de los Power Rangers. Y de Troopers y de los Caballeros de la Mesa Redonda.

119. Niña 2: ¡Ah! Yo no los quiero. Son puras cosas feas.

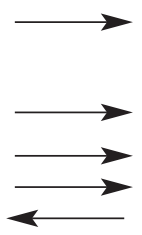

160. Niño 2: Quiero comer cheese cake.

161. Niña 2: Yo le tengo miedo a la noche (se oyen tacones).

162. Niño: Miren el Conde Drácula.

Aquí se observan varias formas de cortesía; ausentes — casi totalmente- en las anteriores categorías. La información es para recordarle al oyente que debe tomar en cuenta lo que dice el hablante para continuar la dinámica del juego. Algunas formas de cortesía son:

28. Niño 1: No, gracias. Porque le voy a ir a comprar unos confititos. ¿Usted qué? ¿Ella quién es?

37. Niña 2: ¡Ay gracias! 
La información genera en algunas ocasiones un cambio de tópico. Además, hace del conocimiento general los intereses y las necesidades en el momento de realizar alguna actividad: momentánea o futura.

\section{Conclusiones}

1. Los niños son capaces de elaborar toda una clase de discurso para lograr los objetivos de sus juegos: ya sea imitar una pulpería o una situación familiar.

2. Esta clase de juegos no necesariamente señala que los niños sean violentos o agresivos, pero refleja una serie de situaciones culturales, sociales o familiares.

3. Las categorías que aparecieron en todos los actos fueron: imperativas, preguntas y respuestas, información y petición. Así,el discurso infantil en estos actos lingüísticos está compuesto por muchas formas de imposición y de órdenes, pero también muestra formas de persuasión y de cortesía.

4. La amenaza solo aparece en el tercer acto: esto demuestra un discurso directo, con pocas formas de persuasión y cortesía en las dramatizaciones infantiles.

5. El discurso está caracterizado por patrones de hablantes y oyentes en una situación como la de una pulpería o la de una familia y las actividades que allí se desarrollan, que posiblemente forman parte de la vida diaria de los niños. Esto señala la capacidad de aprendizaje y enseñanza de los preescolares, de lo que escuchan y observan: es decir, no son sujetos pasivos. Utilizan su capacidad de creación para reflejar sus intereses, necesidades y conocimientos por medio del lenguaje.

6. A pesar de que en algunos momentos lo que parece existir son monólogos colectivos, luego se van creando las situaciones lúdicas para interactuar como los diferentes personajes en la dramatización.

7. Está claro que las formas imperativas están en los tres actos y marcan un estilo de discurso fuerte y de lucha de poder en el juego.

8. Todos los participantes están conscientes de las órdenes que les dan al punto de que tratan de defender su participación con otras estrategias lingüísticas: peticiones y respuestas.

9. Los niños tienen una gran habilidad para crear una serie de situaciones, con lo cual se evidencia el mundo fascinante del lenguaje y su adquisición a esa edad —en todos sus niveles: fonológico, morfológicosintáctico, semántico y pragmático- y su relación con la cultura. Esto resulta interesante porque es aquí donde se contraponen y ligan todas las teorías chomskianas del lenguaje como capacidad innata y por otro lado las tan criticadas por parte de los mismos chomskianos - teorías sociolingüísticas.

10. Es una tarea importante para los estudiosos del lenguaje analizar estas disyuntivas. Este pequeño estudio - con un corpus mínimo- al menos me plantea y demuestra que el contexto — lingüístico y situacional— es fundamental para entender y analizar el habla.

11. De nuevo queda claro que la tarea del lingüista no puede ser unilateral — por lo menos para que tenga mayor validez para la comunidad - sino que debe involucrar varias disciplinas al entender el fenómeno lingüístico. 
12. En el nivel pedagógico, queda evidenciada la tarea fundamental del maestro en relación con el conocimiento teórico y práctico que ha de tener para investigar la función del lenguaje en el aula: cómo se adquiere, para qué sirve, cuáles son las características del discurso, cómo elaborar estrategias de enseñanza y aprendizaje que le permitan al niño un manejo más amplio y desprejuiciado del manejo de la lengua. Que todos estos elementos tienen que ver — como lo señalan Sacks, Brown y Yule, Vigotski y muchos otros autores reconocidos y no reconocidos- con un contexto social y cultural en el cual se desenvuelven los hablantes.

\section{Notas}

* Estudiante de la Maestría en Lingüística de la Universidad de Costa Rica. Bachiller en Educación Preescolar.

\section{Bibliografía}

Bobes Naves, María del Carmen. 1992. El diálogo. Madrid: Gredos.

Brown, Gillian y Yule George. 1993. Análisis del discurso. Madrid: Visor Libros, S.L.

Gumperz, John y Dell Hymes. (Edited by). 1986. Directions in Sociolinguistics. The ethnography of communication. Okford: Blackwell Publishers.

Lee Mckay, Sandra y Nancy Hornberger. (Edited by). 1996. Sociolinguistics and language teaching. Cambridge: Applied Linguistics.

Murillo, Mariélos y Silvia Chacón. 1995. "Las funciones del lenguaje en el aula preescolar". En: Memoria del II Simposio de Educación Preescolar. 145-153. San José: Publicaciones de la UCR.

Ramírez S., Laura. 1996. Actos verbales de niños preescolares en períodos de juego-trabajo y su representación de modelo cultural. (Trabajo final para el curso de Lengua y cultura). San José: SEP-UCR.

Schiffrin, Deborah. 1994. Approaches to discourse. Okford: Blackwell Publishers Ltd. 